\title{
Modeling Water Quality Management Alternatives for a Nutrient Impaired Stream Using System Dynamics Simulation
}

\author{
R. S. V. Teegavarapu*, A. K. Tangirala and L. Ormsbee \\ Department of Civil Engineering, University of Kentucky, Lexington, KY, 40506-0281
}

\begin{abstract}
A system dynamics (SD) simulation model is developed using an object-oriented modeling environment to simulate and analyze water quality management strategies for a nutrient impaired stream. An object-oriented simulation environment, STELLA, conceived on the principles of system dynamics (SD) is used for the development of the model. The modeling process consists of developing stock-flow diagrams and carrying out computer simulations using difference equations to integrate stocks and flows. The model structure and behavior of the system is validated using dimensionality, replication and sensitivity tests; and calibration along with validation is carried out using an appropriate model performance measure. The model helps the user to separate policy questions from the data and provides the facility to generate "what-if" scenarios while keeping the modeling process transparent. Case study application of this model is illustrated by developing a total maximum daily load (TMDL) allocation strategy for a nutrient impaired stream in the southeastern region of Kentucky, USA. Results suggest that the fate and transport process of total phosphorus in a river system can be simulated using a conceptually simple object-oriented simulation model.
\end{abstract}

Keywords: Eutrophication, nutrients, object-oriented modeling, simulation, STELLA, system dynamics, total maximum daily load (TMDL), Kentucky

\section{Introduction}

Nutrients such as phosphorus, nitrogen, and carbon are known to be vital to sustaining aquatic ecosystems. However, an abundance of these nutrients will accelerate the natural eutrophication process of a water body and is also considered to be an interference with desirable water uses (Thomann and Mueller, 1987). Eutrophication, a process stimulated by an increase in nutrients, leads to nuisance algae blooms, or more commonly periphyton (rooted algae) in swift moving fresh waters. Anthropogenic changes to ecosystems and water bodies by means of wastewater treatment effluents in streams and/or agricultural and fertilization practices are typical causes for the imbalance of nutrients concentrations in streams and water bodies.

Nutrient impairment of streams is a common problem plaguing many streams and water bodies in the U.S. (USEPA, 1998). Section 303(d) of the Clean Water Act (CWA) and the Environmental Protection Agency's (EPA) Water Quality Planning and Management Regulations (40 CFR Part 130) require states to develop total maximum daily loads (TMDLs) for their water bodies that are not meeting designated uses under technology-based controls for pollution. The TMDL development process establishes the allowable loadings of pollutants or other quantifiable parameters for a water body based on the relationship between pollution sources and

\footnotetext{
* Corresponding author: ramesh@engr.uky.edu
}

in-stream water quality conditions (Lung, 2001). The TMDL process enables the states to establish water quality based controls to reduce pollution from both point and non-point sources and restore and maintain the quality of their water resources (USEPA, 1998). In order to achieve this objective, the fate and transport of pollutants in streams has to be modeled to facilitate the process of assessing the source and magnitude of the relative pollution load generated by the point and the non-point sources.

The above-mentioned objective highlights the necessity of developing both modeling and environmental policy analysis tools. Limited literature on modeling the fate and transport of nutrients (USEPA, 1999) in water bodies under data-poor situations is currently available. The main difficulty of nutrient/eutrophication modeling is due to non-linear interactions between nutrients and plants (Thomann and Mueller, 1987). Craig et al. (2000) point to difficulties associated with calibration of physically based models and estimation of parameters from limited data. In many situations, the parameters of water quality models cannot be uniquely obtained from the available field data and thus must be estimated from technical guidance documents (Bowie et al., 1985). In such situations, little confidence can be attached to the results of the models (NRC, 2001) and therefore they are not appropriate to evaluate future environmental management scenarios. On the other hand, simple inductive models can provide valuable insights into the processes and at the same time not being highly parameterized. Hodges (1987) and Levin (1985) indicate that overly detailed models are useless as predictive devices and suggest that tech- 
niques for aggregation and simplification are essential. The model selection criteria concerning cost, flexibility, adaptability and ease of understanding all tend to favor simple models, and promote research for development of simpler models that can be fully parameterized from the available data (NRC, 2001).

In this paper, a system dynamics (SD) approach is adopted to model the spatial and temporal variability of total phosphorous (TP) in a nutrient impaired stream in the state of Kentucky, USA. The objectives of this study are: (1) to model the transport and fate of total phosphorous through the 12 miles of impaired stream in the town branch watershed; (2) to develop a TMDL from the obtained model and to generate what-if scenarios; (3) to simulate and analyze water quality strategies for this specific stream and evaluate the outcomes of different possible future scenarios in the region. Earlier study by Ormsbee and Blandford (2001) provided a numerical simulation model that uses kinematic wave theory model for stream under consideration in the current study. Without replicating the earlier work, an attempt has been made to assess the validity of developing simple fate and transport model for total phosphorus in the stream using a system dynamics (SD) modeling approach.

The contents of this paper are organized as follows. An introduction to system dynamics is provided first followed by discussion about object-oriented simulation environment used in the current study. Development of system dynamics model using the basic building blocks of the simulation environment is discussed next. Finally, application of SD model for evaluation of water quality management alternatives for a nutrient impaired stream, results and analysis along with general remarks and conclusions are presented.

\section{System Dynamics Modeling Approach}

System Dynamics (SD) (Forester, 1961) is a concept based on systems thinking where dynamic interaction between the elements of the system is considered to study the behavior of the system as a whole. The main idea of system dynamics modeling is to understand the behavior of the system by the use of conceptually simple mathematical structures. SD concepts can help: (i) describe the system; (ii) understand the system; (iii) develop quantitative and qualitative models; (iv) identify how information feedback governs the behavior of the system and finally, (v) develop control polices for better management of the system. Central to the theme of system dynamics are two important building blocks, stocks and flows that can be used to model the elements that govern the behavior of a dynamic system. The governing equations used for modeling different elements in a system are represented by finite difference expressions and are solved using standard numerical schemes.

\section{System Dynamics and Modeling Environment}

An object-oriented simulation environment, STELLA
(HPS, 2000), is an ideal tool to model any dynamic system. The simulation environment is conceived on the principles of system dynamics. Recent applications of STELLA relevant to water resources management and policy studies and water quality studies were provided by Simonovic et al. (1997), Fletcher (1998) and Nirmalakhandan (2002). Several other studies (Moffatt, 1981; Coyle, 1996; Ford, 1999; Deaton and Winebrake, 2001; Nirmalakhandan, 2002) indicate that the principles of system dynamics are well suited for modeling and application to water resources and environmental problems. System behavior in space as well as time can also be simulated using system dynamics framework (Hugget, 1993). Huang and Chang (2003) in a recent survey of emerging tools for environmental systems analysis indicate the potential of using system dynamics for improved understanding of the environmental systems. Elshorbagy et al. (2002) used system dynamics simulation modeling environment for generating water quality management alternatives for pathogen impaired streams. Teegavarapu et al. (2002) provide a stochastic framework for characterizing pathogen loads in streams using system dynamics simulation with the help of STELLA. The object-oriented simulation environment, STELLA, provides several generic building blocks through which specific components of water and environmental resource systems can be modeled. These basic building blocks referred to as stock, flow, converter and connector are shown in the Figure 1. The generic properties of these objects can be used for modeling a variety of dynamic systems. Table 1 provides a list of water quality processes and environmental systems, and their equivalent modeling objects in STELLA environment.

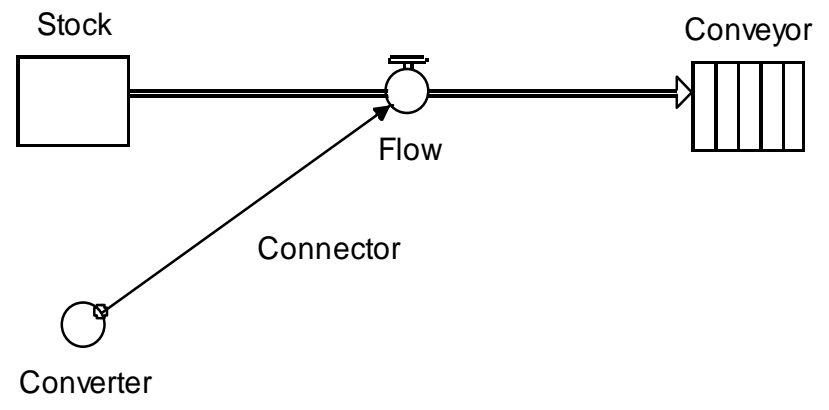

Figure 1. Basic building blocks of the object-oriented simulation environment (STELLA).

\section{Model Development}

The development of water quality model using the object-oriented simulated environment, STELLA is briefly discussed here. The first step in the development of a system dynamics simulation model is the creation of causal loop or influence diagram (Roberts et al., 1983; Moffat, 1991; Sterman, 2001). The diagram is used to identify the main components of the system and their relationship with each other. A causal loop diagram for a river system polluted by a waste water treatment plant (WWTP) is shown in the Figure 2. An 
arrow with a sign indicates the nature of relationship between any two elements. For example, an increase in pollutant loads from the WWTP increases the pollutant concentrations in the stream is represented by a positive sign at the beginning of the arrow. Similarly increase in flow in the river increases dilution and therefore reduces the concentration levels in the stream. More details of the general theory behind development of causal loop diagrams are available elsewhere (Roberts et al., 1983).

Table 1. Processes and Physical Elements that Affect Water Quality and Corresponding Modeling Objects in STELLA Simulation Environment

\begin{tabular}{ll}
\hline Water Quality Components & $\begin{array}{l}\text { Modeling Objects in } \\
\text { STELLA }\end{array}$ \\
\hline $\begin{array}{l}\text { Lakes, Stream Storages, Deposition, } \\
\text { Pollutant loads }\end{array}$ & Stocks \\
$\begin{array}{l}\text { Inflows (stream flows), loads } \\
\text { Mathematical Relationships: (e.g. flow } \\
\text { pollutant load), decay relationships }\end{array}$ & Converters \\
$\begin{array}{l}\text { System boundaries: reaches, Outlets, } \\
\text { Watersheds }\end{array}$ & Sources and sinks \\
Transfer of relationships and links & Connectors \\
\hline
\end{tabular}

The elements highlighted in bold in Figure 2 contribute towards information feedback that will help in improving the water quality of the stream by adopting pollution abatement measures (e.g. total maximum daily load implementation). The material feedback is achieved by physical transfer of quantities between stocks through flows. Since pollution abatement measures will be undertaken through implementation of TMDL, in future the whole system will be governed by a negative feedback behavior which stabilizes the system. This is shown via a -ve sign in the center of Figure 2 following the convention of causal loop diagrams. Once the causal loop diagrams are created, stock and flow diagrams are developed and simulation is carried out using any SD-based simulation environment.

\section{Development of Phosphorous Transport Model using STELLA}

The proposed system dynamics simulation model is developed to understand and model the fate and transport of a nutrient in a stream. To simplify the analysis, the stream system is characterized as plug flow system with negligible dispersion. Assuming steady state conditions, the spatial variability of the concentration along the river is modeled. To model the transport of total phosphorous through the stream an object-oriented simulation environment, STELLA (HPS, 2000), which is conceived on the principles of system dynamics modeling approach is used. The main stream is divided into several reaches. Stocks are created at different reaches which accumulate the loads and then the flow objects pass the loads to the next reach. The loads are thus propagated through flows to the respective stocks and the obtained loads at each stock are again propagated to the next reach taking into consideration the decay represented by a parameter ' $k$ '. Different values of ' $k$ ' are initially assumed for different reaches. The ' $k$ ' parameter is assumed to take into account all the factors like decay, deposition, chemical and biological degradation, etc. Advection and dispersion processes are not considered explicitly in the model. However, it is assumed that these processes are implicitly handled by one single decay coefficient in each reach through a first order decay equation. The total phosphorous concentration is modeled as a substance that decays as a first order process (Thomann and Mueller, 1987) given by the expression:

$$
C=C^{o} e^{-k t}
$$

where $C$ and $C^{0}$ represent the total phosphorous concentration (mg/l) at downstream and upstream reaches respectively, ' $k$ ' is the decay rate $\left(\right.$ day $\left.^{-1}\right)$, and ' $t$ ' is the travel time in days that is estimated from the distance and velocity of the stream. Several assumptions are made to use the simplified concentration equation given in equation (1), and these are: 1 ) the flow rate in the stream is independent of stream length and travel time; 2) the stream cross section is prismatic and constant over time and length and 3) all the reactions are of first order and are consumptive with a rate constant, $k\left(\mathrm{~T}^{-1}\right)$. The equation (1) is solved to predict the spatial and temporal variations of concentration in the stream system. The relationship between dissolved oxygen (DO) and the phosphorus concentration in a stream is not considered in the current study to simplify the modeling process. However, the structure of the model can be easily modified to incorporate such relationship if extensive sampling results of dissolved oxygen and phosphorus concentrations are available. The boundaries of the system are represented by a source and a sink objects representing the starting and ending points of the reach.

The SD model for two representative reaches (A and B) within a river system is shown in Figure 3. The stocks represent the loads that accumulate at different reaches which are propagated through 'Flow' objects. Converters are used to represent the concentrations, flow time series and to represent the first order decay process via mathematical expressions. The connectors pass the information relevant to exponential decay rate from one converter to the other. The object structure (Figure 3) also shows WWTP discharging its effluent in the river between the reaches $\mathrm{A}$ and $\mathrm{B}$. The concentration of the pollutant of interest (i.e., total phosphorus) at the confluence of WWTP and river is calculated using the combined flow and concentration values at the confluence. Dimensionality and replication tests are done on the basic structure of model by checking the integrity of mass balance equations and by assessing the results of the model after it is calibrated and applied to validation data. Sensitivity tests are carried out to assess the response of the model to the different parameters used in the model. 


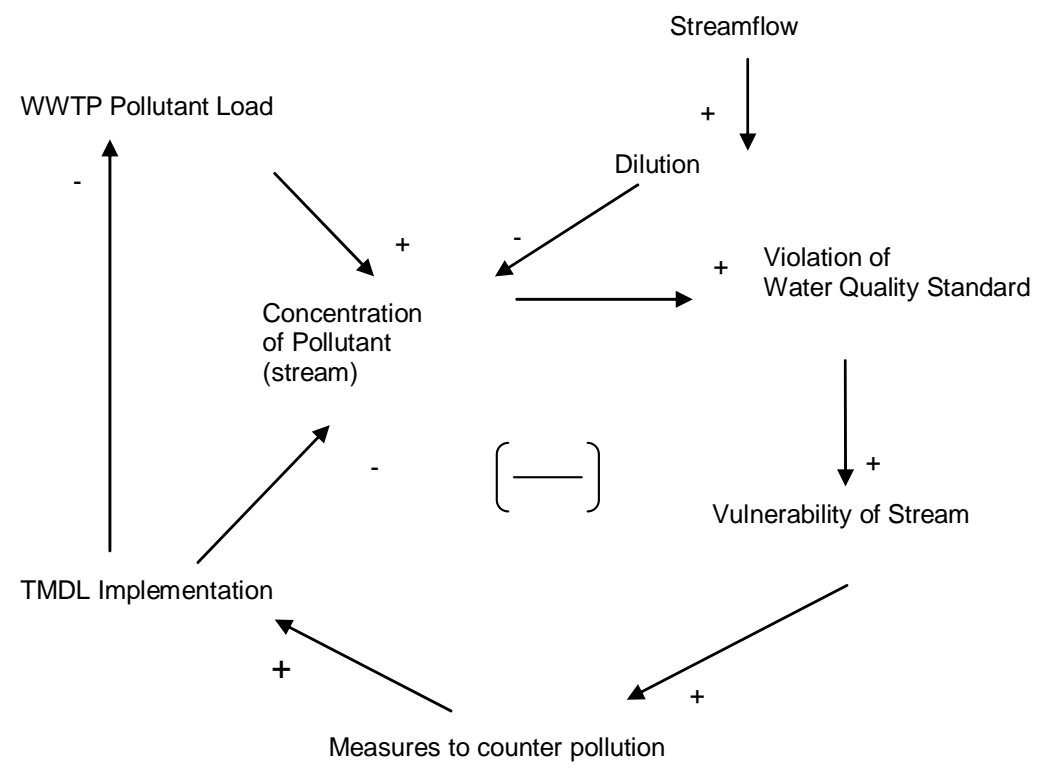

Figure 2. Causal loop (influence) diagram for the WWTP and the stream system.

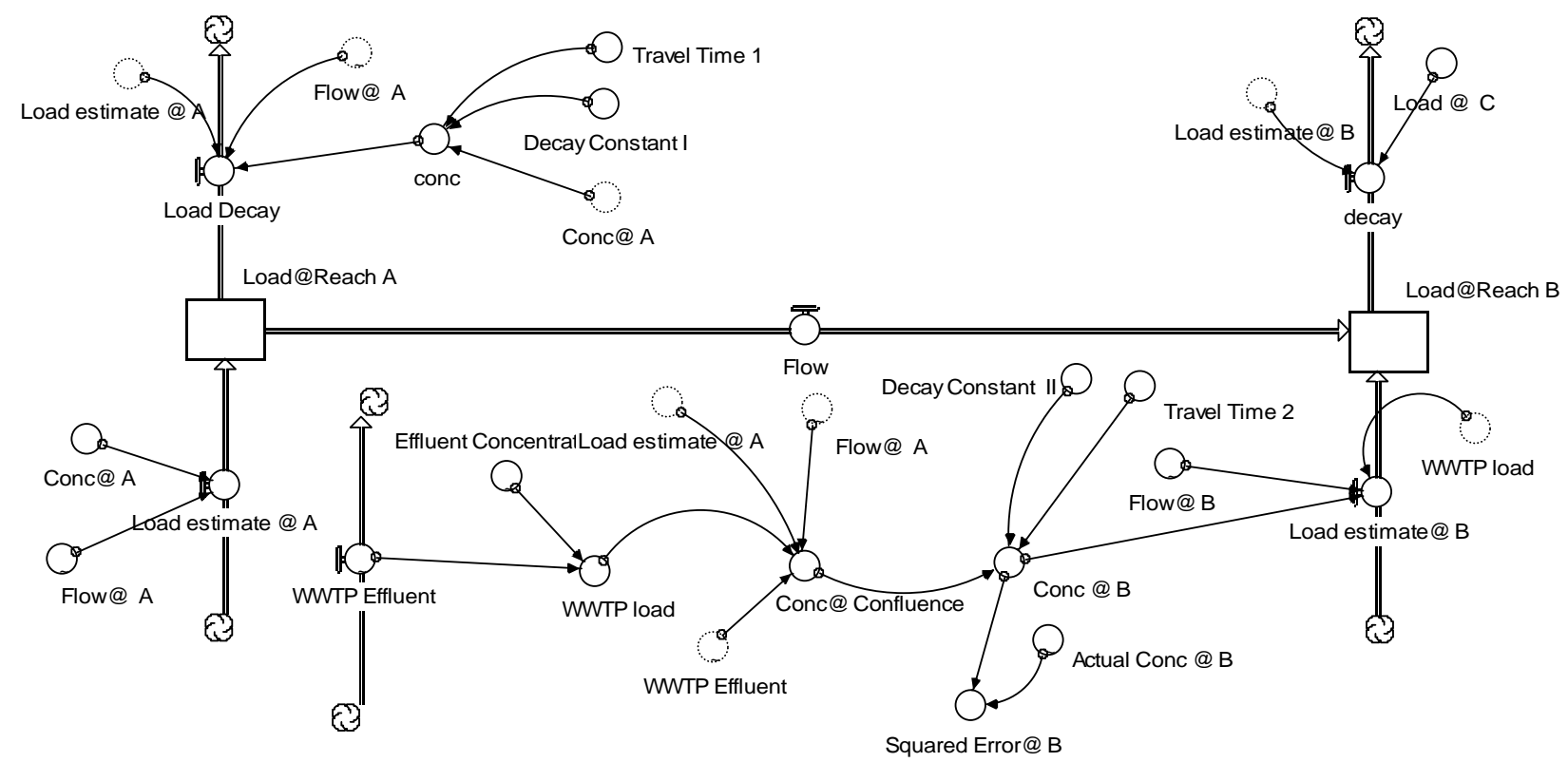

Figure 3. Object structure of the system dynamics model. 


\section{Application of System Dynamics Simulation Model}

The system dynamics model is applied to a nutrient impaired stream in Town Branch watershed of Kentucky shown in the Figure 4. The impairment is mainly caused by the high nutrient loadings from the effluent of waste water treatment plant discharging into the stream and also due to the discharge of nutrients from urban and agricultural runoff in the area. The Town Branch is a third order stream that originates in downtown Lexington and flows northwest where it joins with South Elkhorn Creek at river $54.2 \mathrm{~km}$ (34 mile). The Town Branch main stem is approximately $18.5 \mathrm{~km}(11.5 \mathrm{mi})$ long and drains an area of $94.54 \mathrm{~km}^{2}\left(36.5 \mathrm{mi}^{2}\right)$, most of which the upper part is urban development in the city of Lexington. Since the effluent from the Town Branch wastewater treatment plant (WWTP) constitutes the majority of flow in Town Branch creek, phosphorus concentrations from the treatment plant dominate the total phosphorus loads in the system. The WWTP is shown as a dark rectangle in the Figure 4.

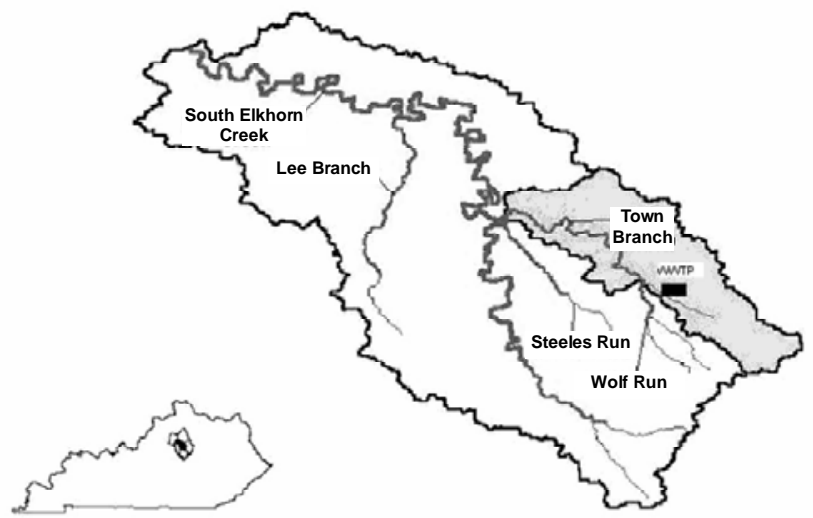

Figure 4. Main streams of Town Branch Watershed with nutrient impaired stream segment in Southeastern part of Kentucky.

The Town Branch watershed is in the Inner Blue Grass physiographic region of the Kentucky. The area is underlain with the Lexington limestone formation of the Ordovician age. Land-use in the Town Branch watershed is grouped into three main categories, urban (5.5\%), rural (44\%) and agricultural, (50.5\%). The headwaters of the basin are heavily impacted by urban and suburban areas. The Town Branch watershed is unique to the nutrient loading quantification, in the sense that background sources play a major factor in non-point source pollution. The geology of the area is dominated by highly phosphatic limestone that creates a significant background source concentration component. This background contribution can yield high concentrations of total phosphorus during high runoff events as well as during low-flow conditions that range from $0.2 \mathrm{mg} / \mathrm{l}$ to $0.3 \mathrm{mg} / \mathrm{l}$. The SD simulation model is applied to a $19.3 \mathrm{~km}$ (12 mile) stretch of Town Branch stream replicating the object structure between any two reaches as shown in Figure 3 to all the reaches. The flow values at all the reaches are obtained from a spatially distributed kinematic wave model developed for the Town Branch stream in an earlier study by Ormsbee and Blandford (2001).

\section{Model Calibration and Validation}

The SD model is calibrated using 3 days of available data in the year 2000 and validated using 2 days in the same year. Measured concentrations of total phosphorus are available at four different points along the 14 mile stretch of the stream. Grab samples were collected using QAQC (quality assurance and quality control) protocol established by Kentucky Water Institute (PRIDE, 2005) for its regional sampling program. The data used for flow objects relevant to treatment plant discharge or streamflow should be continuous values in STELLA as the modeling environment uses a finite difference numerical scheme for computations. Automatic calibration using optimization procedures within STELLA is not possible as it is a simulation environment. Manual calibration to obtain best values of decay parameters is initially carried out by trial and error method and the range of decay parameter value for each reach is ascertained based on visual assessment of simulation results. The model is then iteratively executed by using uniformly distributed random values of parameter (decay, $k$ ) for each reach, within a previously determined range, and the mean squared error (MSE) based on observed and predicted concentrations is calculated for each run. Optimal values of ' $k$ ' are then selected using the lowest MSE criterion and acceptable model performance at each of the reaches. The sensitivity analysis feature of STELLA is used in this process to refine the calibration. The observed and predicted concentration values are shown in the Figures 5 and 6. It is evident from these figures that simulated values of the concentration from the model are in good agreement with those actual measured values.

To assess the effect of the decay parameters on the model performance, model calibration is carried out using two data sets. Data set 1 is the observed data available for the month of June in year 2000 and data set 2 is based on the observed data available for the month of November, in the same year. The results shown in the Figure 7 indicate that the values of ' $k$ ' are higher for data set 2 than the values relevant to data set 1 . While the reasons for this seasonal variation of ' $k$ ' values are not completely obvious but suggest the need for developing two separate models for two different data sets. The model results are sensitive to seasonal variation of decay parameter values. An improved understanding of the seasonal variation of ' $k$ ' values might be possible by collecting more data for calibration and validation. The performance of the model as quantified by MSE improved when two data sets were used to obtain separate decay parameters and are used in the model accordingly in validation.

\section{Results and Discussion}

The calibrated and validated SD model is used for assess- 


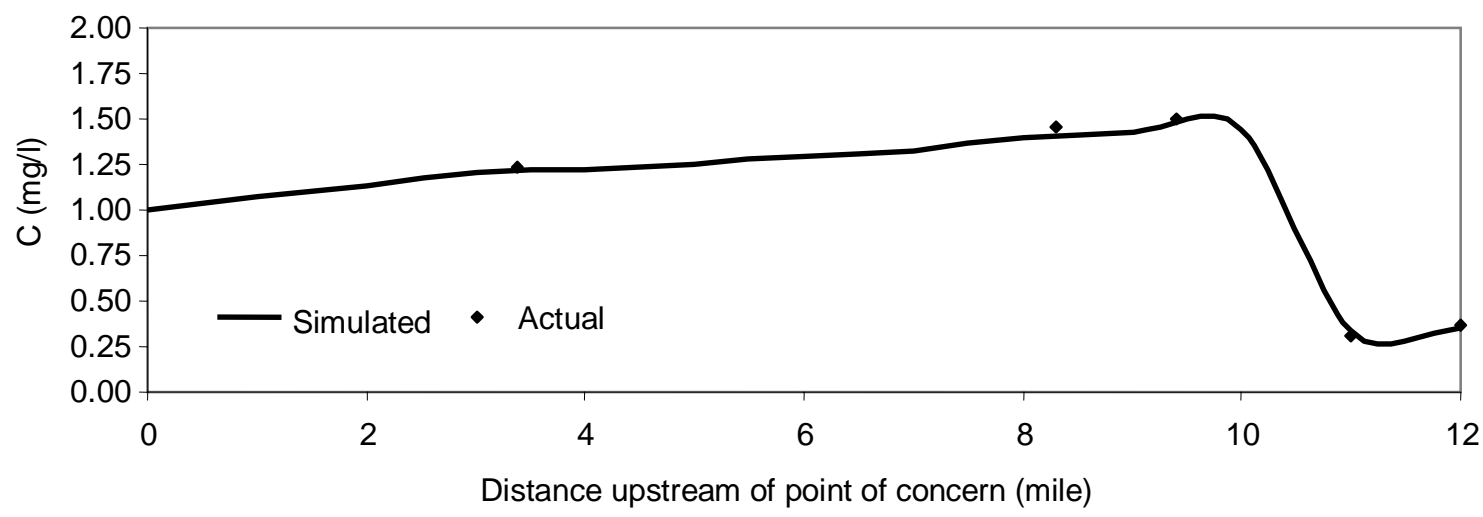

Figure 5. Actual and simulated concentrations in calibration run.

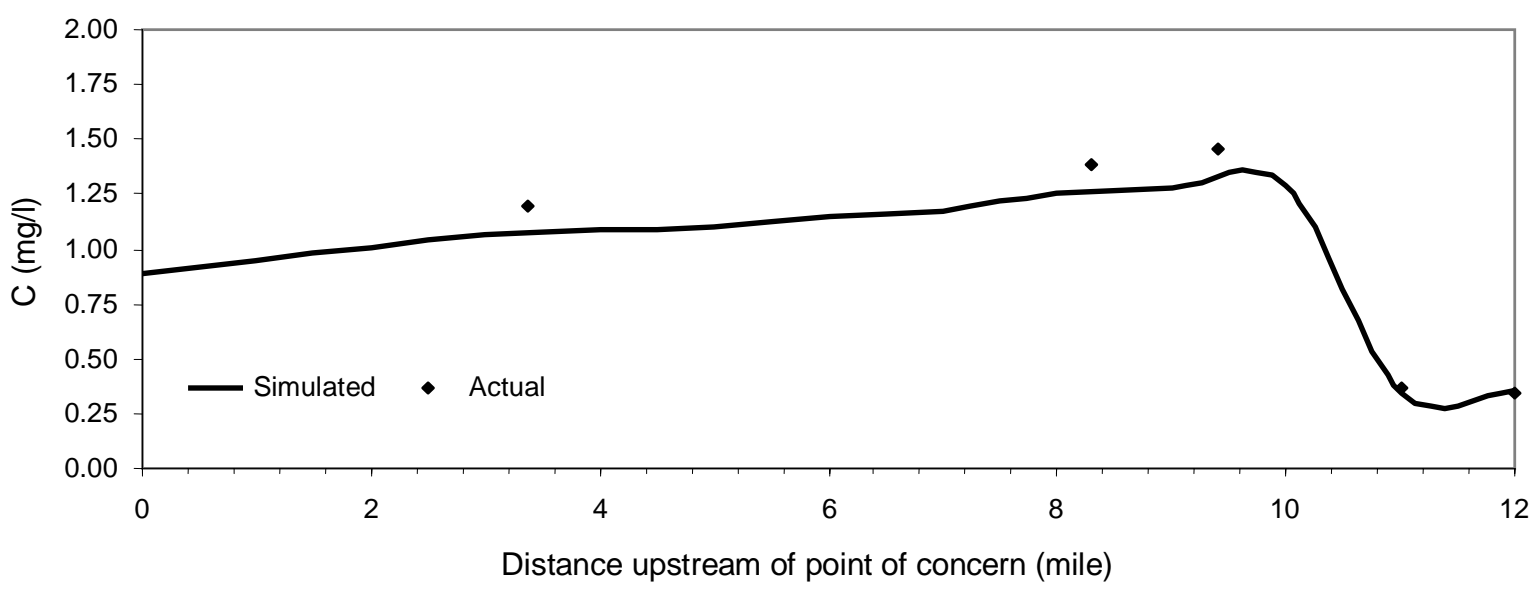

Figure 6. Actual and simulated concentrations in validation run.

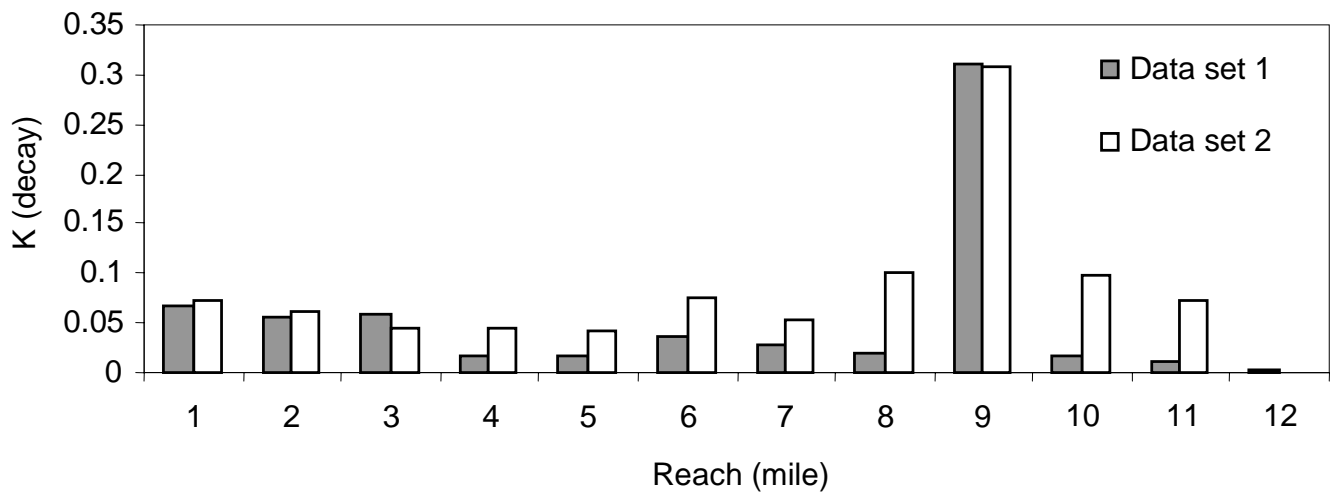

Figure 7. Variation of decay factors along different reaches for two data sets. 


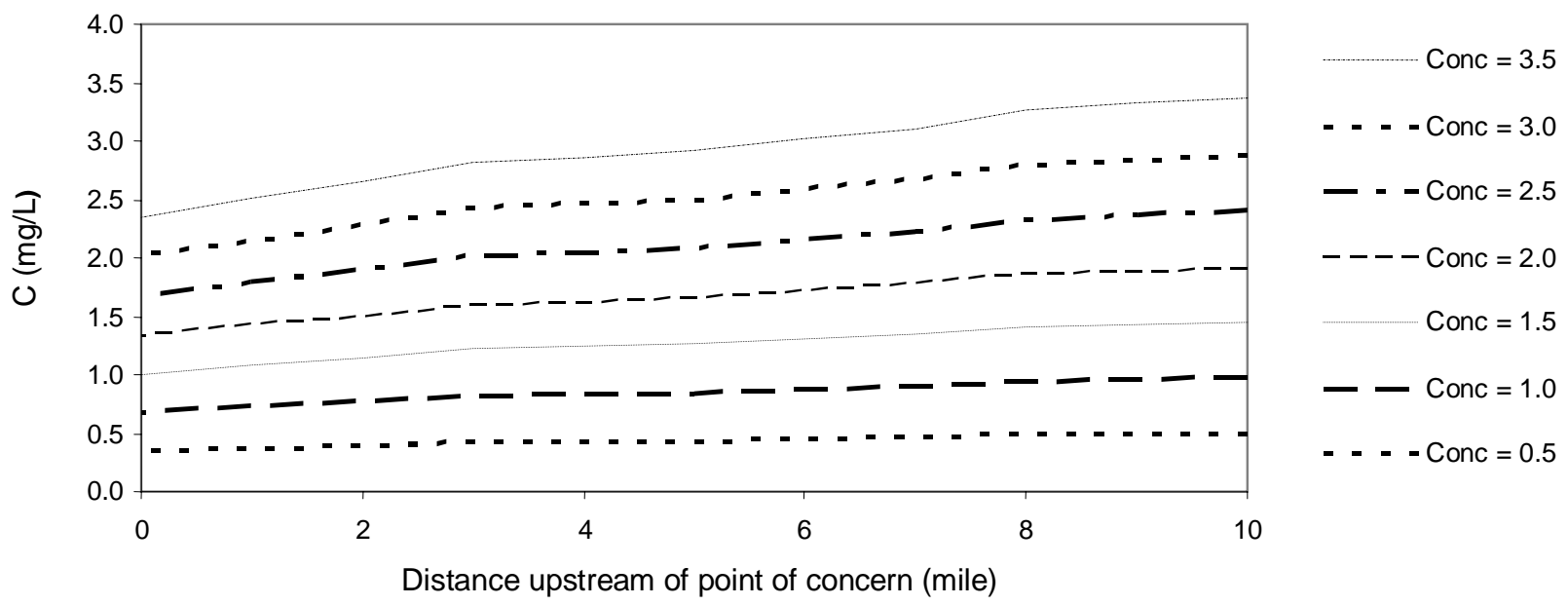

Figure 8. Variation of total phosphorus concentrations for different initial concentrations of WWTP effluent.

Table 2. Impairment at Point of Concern (at Reach 0) Based on Different WWTP Effluent Concentrations

\begin{tabular}{lll}
\hline \begin{tabular}{l} 
WWTP effluent $\begin{array}{l}\text { Concentration } \\
(\mathrm{mg} / \mathrm{l})\end{array}$ \\
\hline 3.5
\end{tabular} & $\begin{array}{l}\text { Maximum concentration at the } \\
\text { point of interest in an year } \\
(\mathrm{mg} / \mathrm{l})\end{array}$ & $\begin{array}{l}\text { Number of } \\
\text { impaired } \\
\text { days }\end{array}$ \\
3 & 2.35 & 365 \\
2.5 & 2.02 & 365 \\
2 & 1.68 & 365 \\
1.5 & 1.35 & 364 \\
1 & 1.01 & 358 \\
0.5 & 0.68 & 336 \\
\hline
\end{tabular}

ment of water quality management alternatives by modifying the loads from point and non-point sources, vulnerability of stream to impairment, and finally the TMDL development. Assessment of water quality is made by modifying point loads from WWTP that dominate the stream pollutant loads under consideration to check any spatial or temporal violations of water quality standard. Effluent concentrations of WWTP ranging from $0.5 \mathrm{mg} / \mathrm{l}$ to $3.5 \mathrm{mg} / \mathrm{l}$ with increments of $0.5 \mathrm{mg} / \mathrm{l}$ are used to determine the concentrations at the point of concern. Figure 8 shows the results of such simulation exercise carried out for the year 1999. Based on the point of concern and water quality standard, load reductions can be estimated at the only source of interest, WWTP. The simulation model is also used to calculate the vulnerability of the stream to nutrient impairment by finding the number of days the stream is impaired if an acceptable concentration level for total phosphorus is set at any point of concern. To assess the vulnerability of stream, the acceptable value of concentration at the point of concern (reach at 0 mile, shown in Figure 8 ) is set at $0.5 \mathrm{mg} / \mathrm{l}$. Results provided in the Table 2 indicate that effluent concentration from WWTP should be equal to 0.5 $\mathrm{mg} / \mathrm{l}$ to achieve the status of no impairment at the point of concern.

\section{TMDL Development}

The total maximum daily load (TMDL) describes the maximum amount of pollutant a stream can assimilate without violating water quality standards. TMDL is comprised of the sum of individual waste load allocations (WLA) for point sources, load allocations (LA) for non-point sources and margin of safety (MOS) that accounts for uncertainty in the relationship between pollutant loads and the quality of receiving water body. A TMDL is generically described by the following equation:

$T M D L=\sum(W L A)+\sum(L A)+M O S$

In the development of TMDL for the impaired stream under consideration, load allocations which reflect for non-point sources are not considered as concentrations related to background sources (non-point sources) are already considered in the simulation model. The margin of safety is generally included in the TMDL in an implicit manner by using conservative model assumptions to develop allocations (USEPA, 1991, 1999b). This is achieved in the current study by using conservative estimates of background concentrations.

The existing waste water treatment plant in the Town Branch watershed is considered to be the major point source contributing to the pollution at the downstream point of concern and the TMDL is developed accordingly. No load allocations are sought for non-point sources and the total maximum daily load is obtained by limiting the WWTP effluent to permitted design discharge (i.e. 30 million gallons per day) and estimating the load reductions for achieving the required water quality standard at the point of concern. In the current study, this is achieved by using a critical flow year guided by 
lowest six month average flows in year selected from years 1980 to 2000. The critical year was found to be year 1999 for the stream under consideration in the current study.

The state of Kentucky currently has no official numerical (water quality) standard or criterion for total phosphorus or total nitrogen. The USEPA has recently issued recommendations for phosphorus concentrations to prevent nutrient over-enrichment. In general, any concentration of phosphorus in excess of $0.1 \mathrm{mg} / \mathrm{l}$ has the potential to cause eutrophication in a stream. However, the trigger values of concentrations for onset of eutrophication vary from one water body to another and therefore these values are not fixed. Numerical targets of nutrient concentrations expressed as total phosphorus (TP) are generally used to address the nutrient availability issue in streams (USEPA, 1999a). In one scenario to develop the TMDL the allowable concentration at the point of concern (reach at 0 mile, shown in Figure 8 ) is set at $0.7 \mathrm{mg} / \mathrm{l}$ and the effluent concentration from WWTP is set at observed six-month average value of $2.2 \mathrm{mg} / \mathrm{l}$. To achieve in-stream total phosphorus concentration below $0.7 \mathrm{mg} / \mathrm{l}$ at the point of concern, the Town Branch WWTP effluent concentration must be reduced from observed six-month average of $2.2 \mathrm{mg} / \mathrm{l}$ to approximately $1.0 \mathrm{mg} / \mathrm{l}$. It is evident from the Figure 8 that the effluent concentration of $1.0 \mathrm{mg} / \mathrm{l}$ of WWTP will result in the $0.63 \mathrm{mg} / \mathrm{l}$ at point of concern. Therefore the allowable load should be derived based on the effluent concentration and discharge of WWTP. Using maximum effluent concentrations of $2.2 \mathrm{mg} / \mathrm{l}$ and $1.0 \mathrm{mg} / \mathrm{l}$ from the Town Branch WWTP (with the current permitted daily discharge of 30 MGD (46.4 cfs) would yield 550 and $250 \mathrm{lb} /$ day of phosphorus loads respectively. The waste load reduction for WWTP is equal to the difference of observed six-month average load and allowable load, i.e., $300 \mathrm{lb} /$ day and finally the TMDL is $250 \mathrm{lb} /$ day. Based on allowable concentration limit at point of concern and permitted discharge of WWTP and for any specific chosen critical year, the TMDL will correspondingly change. The need for TMDL development itself can also established based on the concept of vulnerability. This is achieved by simulating the model under real-time conditions and observed data to assess the impairment. The SD modeling environment facilitates the user to look at several water quality management options by either changing the user-defined parameters of the system or modifying the structure of the model.

In the current study a dynamic modeling environment is used to develop a conceptually simple fate and transport model for total phosphorus in a stream. STELLA is often referred to as dynamic modeling environment which can handle temporal complexity (Hannon and Ruth, 1997; Costanza and Gottlieb, 1998). However, spatial representation of the physical system is also possible using STELLA as demonstrated by the model developed in this study. Simulation models developed using system dynamics principles are designed to understand the basic structure and behavior of the physical system. Therefore, trends in the results or alternative policy decisions derived based on the model results are often times necessary than the actual numerical values obtained through the simulation. Simulation models developed using spreadsheet pro- grams lack transparency and modeling environment that allow the modeler to study the structural and behavioral aspects of the processes included in the model.

\section{Conclusions}

A system dynamics simulation model is developed for modeling the fate and transport of total phosphorus in streams. The model is developed using an object-oriented simulation environment that provides a transparent modeling platform that can answer a number management and policy questions and assess the vulnerability of impaired streams. The simulation model is also used to develop a water quality management strategy (e.g. TMDL) for improving the health of the stream. Conceptually simple dynamic modeling approach such as system dynamics simulation provide best insights into the system and its behavior when the measured data relating to physical systems are scarce. The model application to a case study suggests that the development of simple models under data-poor conditions can provide valuable insights into the fate and transport of the pollutants in river systems.

\section{References}

Bowie, G.L., Mills, W.B., Porcella, D.B., Campbell, C.L., Pagenkopf, J.R., Rupp, G.L., Johnson, K.M., Chan, P.W.H., Gherini, S.A. and Chamberlin, C.E. (1985). Rates, Constants, and Kinetic Formulations in Surface Water Quality Modeling, EPA/ 600/3-85/040, US Environmental Protection Agency, Washington, DC, USA.

Costanza, R. and Gottlieb, S. (1998). Modeling Ecological and Economic Systems with STELLA: Part II. Ecol. Model., 112, 2-3, 81-84.

Coyle, R.G. (1996). System Dynamics Modeling: A Practical Approach, CRC press, Boca Raton, USA.

Deaton, M.L. and Winebrake, J.I. (1999). Dynamic Modeling of Environmental Systems, Springer-Verlag, New York, USA.

Elshorbagy, A., Teegavarapu, R.S.V. and Ormsbee, L. (2002). System Dynamics Approach for Water Quality Management in South Eastern Kentucky, Volume 2, \# 47, Developments in Water Science, Computational Methods in Water Resources, S.M. Hassanizadeh, R.J. Schotting, W.G. Gray and G.F. Pinder (Eds.), pp. 1557-1564.

Fletcher, E.J. (1998). The use of system dynamics as a decision support tool for the management of surface water resources, First International Conference on New Information Technologies for Decision Making in Civil Engineering Montreal, Canada, pp. 909-920.

Ford, A. (1999). Modeling the environment, An Introduction to System Dynamics Modeling of Environmental Systems, Island press, Washington, DC, USA.

Forester, J.W. (1961). Industrial Dynamics, MIT Press.

Hannon, B. and Ruth, M. (1997). Modeling Dynamic Biological Systems, Springer-Verlag, New York, USA.

High Performance Systems (HPS) (2000). STELLA Reference Manual.

Hodges, J.S. (1987). Uncertainty, policy analysis, and statistics (with discussion). J. Am. Stat. Assoc., 2, 259-291.

Huang, G.H. and Chang, N.B. (2003). Perspectives of environmental informatics and systems analysis. J. Environ. Inf., 1, 1-6.

Huggett, R. (1993). Modeling the Human Impact on Nature, Oxford 
University Press, NY, USA.

Levin, S.A. (1985). Scale and predictability in ecological modeling, in Modeling and Management of Resources under Uncertainty, T.L. Vincent, Y. Cohen, W.J. Grantham, G.P. Kirkwood and J.M. Skowronski (Eds.).

Lung, Wu-Seng (2001). Water Quality Modeling for Wasteload Allocations and TMDLs, John Wiley \& Sons, New York.

Moffatt, I. (1991). Causal and Simulation Modeling using System Dynamics, Concepts and Techniques in Modern Geography, CATMOG, Australia.

Nirmalakhandan, N. (2002). Modeling Tools for Environmental Engineers and Scientists, CRC Press, Boca Raton, USA.

NRC (2001). Assessing the TMDL Approach to Water Quality Management, National Academy Press, Washington, DC, USA.

Ormsbee, L. and Blandford, P. (2001). Total maximum daily load development for town branch, Kentucky department of environmental protection. http://www.water.ky.gov/dow/townbr.pdf (accessed, January 2004).

PRIDE (Personal Responsibility in Desirable Environment) (2005). http://pride.uky.edu (accessed, April 2005).

Roberts, N., Andersen, D., Dea, R., Garet, M. and Shaffer, W. (1983). Introduction to Computer Simulation: A System Dynamics Approach, Productivity Press, Portland, OR.

Simonovic, S.P., Fahmy, H. and El-Shorbagy, A. (1997). The use of object-oriented modeling for water resources planning in Egypt. Water Resour. Manage., 11, 243-261.

Sterman, J.D. (2001). Business Dynamics: Systems Thinking and Modeling for a Complex World, McGraw Hill, NY, USA.

Stow, C.A., Borsuk, M.E. and Reckhow, K.H. (2000). Nitrogen TMDL Development in the Neuse River Watershed: An Imperative for Adaptive Management, Project Report, Environmental Sciences and Policy Division, Nicholas School of the Environment and Earth Sciences, Duke University.

Teegavarapu, R.S.V., Elshorbay, A. and Ormsbee, L. (2002). Characterizing pollutant loadings in streams using system dynamics simulation, extended abstract, Proc. of AWRA Annual Conference, W. Claire (Ed.) TPS-02-4, Middleburg, Virginia, pp. 247.

Thomann, V.R. and Mueller, J.A. (1987). Principles of Surface Water Quality Modeling and Control, Harper and Row Publishers.

USEPA (1998). National Water Quality Inventory, Office of Water, US Environmental Protection Agency.

USEPA (1991). Guidelines for Water Quality-Based Decisions: The TMDL Process, EPA 440/4-91-001, Washington, DC, USA.

USEPA (1999a). Protocol for Developing Nutrient TMDLs, USEPA, EPA 841-B-99-007, Washington, DC, USA.

USEPA (1999b). Draft Guidance for Water Quality-Based Decisions: The TMDL Process, EPA 841-D-99-001, Washington, DC, USA. 